\title{
Team-Based Learning in the Design Modules of a New, Integrated, 2nd Year Curriculum at UBC
}

\author{
Antony J Hodgson, Peter Ostafichuk and James Sibley \\ Department of Mechanical Engineering \\ University of British Columbia \\ ahodgson@mech.ubc.ca
}

\begin{abstract}
The Department of Mechanical Engineering at $U B C$ restructured its entire second year curriculum last year (2004-2005) to address numerous deficiencies associated with the conventional instructional model of numerous separate courses with a heavy lecture component. The design portion of the curriculum underwent the most dramatic restructuring - it is now taught in two blocks of four and three weeks, respectively, and the students learn in a thoroughly team-oriented modality which permeates all aspects of the course. In this paper, we explain the rationale for the structure of the design course, describe in detail how the course works, and provide a preliminary assessment of the impact on students' learning.
\end{abstract}

\section{INTRODUCTION}

The Department of Mechanical Engineering at the University of British Columbia (UBC) has just completed the first year of an innovative new curriculum in engineering education. The program, known as Mech 2, is a carefully designed approach aimed at developing second year mechanical engineering students' analytical, practical, and design skills. Mech 2 is taught by a team of instructors and is fully integrated in content and delivery. It aims to foster crossconnections between the various sub-disciplines of mechanical engineering and related subjects in electrical engineering, materials science and mathematics. Design plays an important role in the new course format. Mech 2 completely replaces a conventional course-based curriculum for the approximately 120 second year mechanical engineering students at UBC.

In a traditional engineering program, students take many diverse courses at the same time and spend a great deal of energy juggling disconnected assignments, projects and mid-term exams. A consequence of this system is that most students tend to compartmentalize information according to specific courses and they do not see the connections between related topics. The timing of related material from different subjects is often left to chance; required background material in one course may come from another course but not be presented at an appropriate time. In the terms of design, the conventional curriculum does not facilitate communication and collaboration between instructors of engineering science and engineering design.

In the Mech 2 program, students take only four courses and they complete them in series. The program and the courses are structured to ensure good communication within a team of instructors who together cover all disciplines. The first course (MECH 220) is a four week practicum in which students rotate through four one-week workshops in machine shop practice, instrumentation and electronics, CAD, and drafting. The second course (MECH 221) is ten weeks long and covers material in engineering science including rigid body dynamics, solid mechanics, mathematics, materials engineering, and electrical circuits. The second half of Mech 2 begins in January with four weeks of a design course (MECH 223) in which the students apply material from $\mathrm{MECH} 221$ to a practical design project. The projects culminate with a competition between all the student teams followed by formal oral presentations and the submission of formal written reports. The remaining course (MECH 222) is an engineering science course that covers thermodynamics, fluid mechanics, and mathematics. It is taught over a seven week period using the same structure as the first term engineering science course (MECH 221). After the completion of MECH 222, there is a second MECH 223 design project, this time lasting three weeks and focusing on thermodynamics and fluid mechanics.

All courses in Mech 2 have the same general schedule: Thursdays are left free for field trips or other major events; the remaining four days 
begin with a problem session and have 3 hours of class time, along with dedicated slots for labs, design studios, computer labs, shop time or team meeting times.

The integration in Mech 2 supports the design component by ensuring students have the necessary background before they begin practical design exercises. During the engineering science courses, students receive instruction in the theory that underlies the projects. Likewise, as students begin their design projects in $\mathrm{MECH} 223$, they receive lectures on design theory, workshops on group dynamics, and computer labs on CAD and material selection. Finally, the MECH 220 practicum prepares students for the construction of physical devices and the preparation of supporting drawings required in the design projects.

\section{TEAM-BASED LEARNING}

A team-based structure is central to the new design modules and is used in every aspect of the course. We adopted this structure for two main reasons: (1) engineering is, at heart, a teambased enterprise - virtually all real engineering work is done in teams and we consider it crucial to introduce students to teamwork as early in their studies as possible, and (2) numerous research studies have shown that team-based learning is far superior to conventional instructional techniques almost without regard to subject area.

The particular version of team-based learning (TBL) we adopted is based on the work of Michaelsen [ref]. TBL can be considered to be a form of active or cooperative learning, but it embodies significant philosophical differences. In particular, most cooperative learning advocates recommend that significant effort be put into instruction on proper team functioning, whereas TBL advocates argue that the correct incentive structure naturally leads to productive interactions. We adopted a middle road - we included some direct instruction in team functioning and provided structured opportunities for offering feedback to teammates, but we also used the structural incentives described by Michaelsen and found that they did substantially mitigate problems that many people have experienced with group work.

The general principles of Michaelsen's version of TBL include the following:

- Heterogeneous groups of $\sim 6-8$ students
- Individual accountability

- Team assignments that promote both learning and team development

- $\quad$ Frequent and immediate feedback

In general, the approach turns conventional instruction on its head. In conventional classes, instructors ask their students to do the readings in advance, but do not really require them to do so, so class effectively becomes the place to introduce concepts and work out simple examples. More complex examples get worked out in problem sessions or by the student working alone after class hours. In TBL, the students do their preliminary learning through assigned readings in preparation for a 'Readiness Assurance Process' quiz (RAP) which precedes the first class session on a topic. Problem sessions with a TA allow students to work through simple problems and concepts prior to class. In class, students are asked to work with their teams on more complex problems and to present their results to other teams or to the whole class. A course is generally broken into several modules, each lasting about 6-8 class hours. In our course, each module begins with a RAP and then follows it up with several problem sessions interwoven with several 2 or 3 hour class periods. These ideas are described in more detail below.

\section{Heterogeneous Groups:}

Students most often want to work in homogeneous groups - they want to be with their friends and not engage in the difficult work associated with learning to get along with a group of new people. However, homogeneous groups do not contain the breadth of experience that allows each individual to make a distinct contribution to the overall team's functioning and it is not a good model for future work life.

In UBC's mechanical engineering program, we have the added issue that the students taking Mech 2 are registered in one of two programs: the standard mechanical engineering program (90 students) or the mechatronics program (30 students). In the two earlier courses (MECH 220 and 221), the mechatronics students were placed in their own sections for labs and problem sessions, so they were not as well integrated into the whole class. Timetable and room and equipment/workstation constraints required that we section our course into four groups of 30 students for labs and problem sessions, so in the design course we purposely mixed the 
mechatronics students in with the rest of the class to ensure that each group of 30 students had access to the unique perspective possessed by these students.

We called each group of 30 students a division and named them after a famous mechanical engineering designer of the past century: Edison, Fuller, Goddard and Henry (in previous classes, the sections were named after famous applied scientists: Archimedes, Bernoulli, Carnot and Da Vinci). We further subdivided the divisions into 5 teams of 6 members each and ensured that there were 1 or 2 mechatronics members on each team. Furthermore, we carefully selected each group's members to ensure that we had heterogeneity in psychological profile (according to the MeyersBriggs personality assessment tool), grades in previous courses, tool handiness, communication and language ability, and even car ownership. This heterogeneity ensures that each team benefits from a variety of different perspectives, skills and resources. The teams stayed together throughout the entire course.

\section{Individual Accountability:}

Many instructors and students have been disappointed with their experiences of group work - often one student does not do what the others expect of them (i.e., is a free-rider) or some students decide that it is too much bother to keep some of the other students in the loop. These problems are often exacerbated as group size increases, but can show up even in relatively small groups of 3 or 4 members. Four important structural reasons for this in many versions of group work are:

- Lack of individual accountability

- Difficulty meeting outside class

- $\quad$ Large group reports

- Global group marks

In TBL, individuals are accountable for their preparation, primarily that associated with doing the assigned readings prior to taking the Readiness Assessment Process quiz that begins each block of work. The RAP quiz is described in more detail below, but is taken first by the students individually and subsequently by the team as a whole. The peer pressure associated with trying to maximize the team's mark ensures that students feel a strong commitment to individual preparation prior to class.
The team-based structure of TBL ensures that difficulties in meeting with one's group are minimized because class time is allocated to team discussion. Individual preparation is left to outside class hours, so students can prepare for their team work according to their own schedules.

Traditional group reports actually diminish team interaction because each student typically gets assigned responsibility for one section of it and the final product is a mishmash of the various contributions. There is often much stress involved in the final assembly and editing, especially if one or more components come late and/or are judged inadequate by others on the team. With TBL, the team reporting is almost always comparatively simple (typically a recommendation of some form - see below), but this recommendation follows extensive analysis and discussion. During the discussion as the team attempts to formulate its final recommendation, team members rely on one another's individual preparation and contributions to inform their decision, and students are subjected to strong peer pressure to ensure that their contribution is up to the expected standard.

Finally, in traditional group work, the whole group receives the same mark. This almost always leads to feelings that the marking is unfair because it fails to differentiate between the contributions of the different group members and implicitly encourages 'free-riding'. With TBL, the students are told in advance that they will have an opportunity to evaluate one another's work, and this peer assessment acts as a multiplier on the team grade. There is therefore an incentive for each student to ensure that they are perceived by the team as having made contributions comparable to everyone else.

\section{Team Assignments:}

In TBL, the design of team assignments is critical - proper design promotes both content learning and team development. In traditional group work, the product of teamwork is a large document - a report, a presentation, a model, etc. In TBL, the product is quite simple - a decision, a choice or a recommendation, for example. Such assignments typically generate high levels of user interaction, whereas traditional products of teamwork often lead to students dividing up the work and completing it individually, which limits interaction. We will present examples of our team assignments below. 


\section{Frequent and Immediate Feedback:}

One of the strongest motivators for learning is rapid feedback on whether a learning activity helped students achieve their learning goals. The TBL approach provides two main ways of obtaining this rapid feedback - RAP quizzes and in-class reporting of team assignments.

\section{RAP Quizzes:}

As mentioned above, we assign readings at the beginning of each block and administer the quiz in the first class of the block. The RAP quizzes are structured as multiple choice tests that assess two main things: students' basic comprehension of concepts found in the readings and their ability to apply the concepts to simple situations. Examples of these two types of questions follow:

Basic Comprehension: Which of the following statements is NOT true of "technology push" products?

\section{A. Gore-Tex is a good example}

B. Breakthrough products are typically introduced this way

C. The product development process is much riskier than "market pull" developments

D. A specific product does not typically have to be identified in advance of development

Simple Application: Which of the following business strategies is likely to carry the least financial risk for a company that has developed a new material?

A. Identify a market for and develop a single product based on the new material

B. Develop a range of forms and sizes of the material to sell as stock material to other businesses who will use the material in their products

C. Develop a manufacturing plant which can turn out the material in a wide variety of forms and sizes, but manufacture only in response to orders from other businesses

Although these quizzes are multiple choice, they are not easy - typical scores for individuals average about $50 \%$. Once students finish taking the quizzes individually (which takes about 2025 minutes), they hand in their answer sheets and immediately start working on them in their teams. While they are taking the quiz as a team, their individual exams are scored electronically.
The team answer sheets are of the 'Scratch \& Win' variety - when the students have chosen an answer and scratched off the corresponding spot, they find out if they are correct or not. If not, they are allowed to scratch again up to twice more; they receive 4 points if they get the correct answer on the first scratch, 2 on the second, and 1 on the third. The point, however, is that they find out immediately whether or not they are right.

When the teams finish their quizzes, we project the aggregated results from the individual quizzes on the board, along with a detailed breakdown of what the answer distributions were for each question. We then have a brief, focussed discussion about the questions that the students feel they understand the least AFTER having discussed the question with their teammates and learning the correct answer; this debriefing is very high-energy and productive since the students are highly motivated to learn about issues that neither they nor their teammates understand. The students also quickly learn which of their teammates have held back in the team discussions - if a student got an answer right but did not persuade their teammates (either because they were shy or because their teammates did not let them speak), the team is highly motivated to listen to that student in the future. Interestingly, the team typically outscores their best individual by $10-15 \%$, although this 'superscore' usually only occurs once teams learn to value the thoughts of members other than the top individual.

\section{In-Class Reporting of Team Assignments:}

Traditional team assignments require complex write-ups and take a considerable amount of time to mark - students often do not get the material back for days or even weeks. By this time, they have forgotten the assignment and the feedback loop is not properly closed.

With TBL, the assignments require the students to make a decision that is easy to report in class. For example, in our course, we gave an assignment that lasted three class hours. Students were given a crash course in mechanical components and principles of sizing them, and then asked to roughly design a mechanism for lifting a rocker arm using either a hydraulic cylinder or an electric motor. Each group was required to report the estimated cost of their device by posting their estimated cost on the board at the front of the classroom, and the 
mark they received was inversely related to the cost they reported.

However, before marks were assigned, there was a class discussion in which the various teams were allowed to ask questions of other teams and challenge their designs. If a team could not support its decisions in light of a challenge from another team, they were forced to withdraw their design and re-estimate their costs. The design that got the best mark was therefore the one that survived challenges and had the lowest cost at the end. This marking scheme made it impossible for students to do the assignment half-heartedly - if they made poor estimates, their costs were high, and if they neglected key components, their design would be found out through challenges from other students. In general, we found that this assignment was very successful, although we did find that students are initially not all that good at explaining their designs or presenting the justifications for their decisions, so it is challenging to keep the whole class discussion at a high energy level. However, we think that presenting technical work effectively is a key professional skill and well worth developing through practice, so this is not a reason to not do these assignments.

\section{TOPICS IN MECH 223 \& OVERALL COURSE DESIGN}

The overall purpose of this first course in design is to introduce students to the generic design process, to familiarize them with the key mechanical components and fabrication processes, to make them aware of the broader context within which design is done, and to give them practice in applying the design process to a real project, supporting their design choices with engineering analysis and presenting and discussing their work.

To accomplish these goals within the overall design of the Mech 2 program, we opted to offer the design course in two blocks - one of 4 weeks in length and the other of 3 weeks.

The first design block introduces students to the design process and offers a 'crash course' in mechanical components and fabrication, while the second block addresses the process of refining designs and brings in concerns such as failure mode analysis, ergonomics, design for assembly, and intellectual property issues. Integrated throughout the course is material on material selection, technical writing and presentation, and professionalism.

\section{SPECIFIC COMPONENTS OF MECH 223}

We have already discussed several key components of the design course, MECH 223. These include the readings, the Readiness Assurance Process quizzes, and the in-class assignments. In addition to these components, we used various other class assignments, along with problem sets, computer labs, design and machine shop sessions, various special tutorial sessions, and two major design projects. These other elements are briefly outlined below.

\section{Class}

In addition to the in-class team exercises described above, we offered students two opportunities to closely examine a common electromechanical system - an inkjet printer. In the first session, students had been introduced to the major classes of mechanical components and were then asked to take apart the printer in order to identify how the various parts were used to accomplish various functions. In the second session, students disassembled the printer in order to assess how well the designers observed the principles of Design For Assembly.

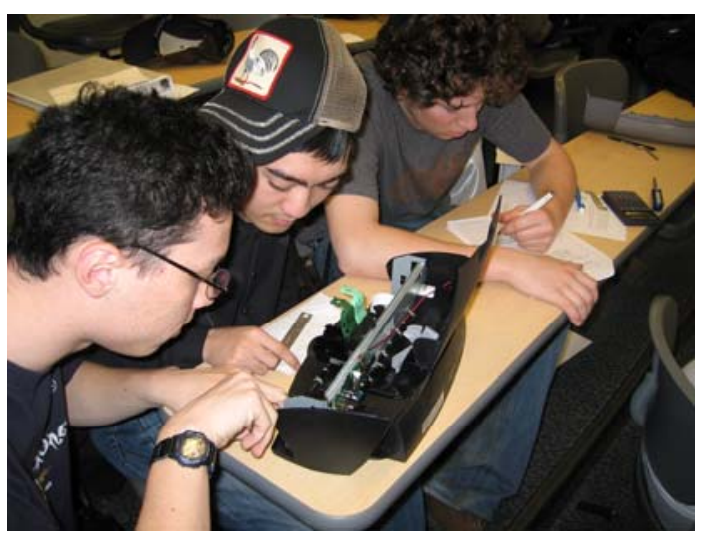

Figure 1. 'Hands-on' in-class exercise students study the mechanical components used in an inkjet printer.

\section{Problem Sets}

When we first designed this course, we treated the problem sets the same way we would in a conventional course - that is, as an occasion for the students to work on more complex problems than they could handle in class. However, we soon learned that the kinds of problems that we wanted students to work on required them to develop and exercise judgement, and the TAs were uncomfortable guiding the students in this role. We therefore switched the format of the problem sets during the second block. We 
classified all the learning objectives we had come up with for the course into Knowledge, Skills or Judgement. For the most part, we had students develop their knowledge through the assigned readings, skills through the problem sessions (augmented with mini-lectures of 5-20 minutes in class) and judgement through the team assignments. This switch in emphasis from judgement to skill in the problem sessions enabled the TAs to feel much more comfortable leading these sessions.

\section{Projects}

Each block also features a challenging design project strongly related to the material presented in the preceding integrated module. The first project this year was inspired by the CassiniHuygens mission to Saturn and Titan. It focused on kinematics, dynamics, electronics, and materials and involved an increasingly difficult series of challenges on a two-dimensional inclined playfield. Students had to design, build, and operate a ballistically-launched vehicle (Cassini) that had to travel along the playing surface and then release a second vehicle (Huygens) towards a target. Teams were awarded points for launching automatically by referencing an electronic launch signal, for separating the Cassini and Huygens vehicles in a zone that was defined at the start of each round of competition, for having Huygens reach a target (representing the moon Titan), and for having Cassini reach the end of the table with position and velocity appropriate for orbit around Saturn. Score bonuses and penalties were then applied based on the weight and cost of the vehicles, and on the time required to complete the mission. A photograph from the competition is shown in Figure 2.

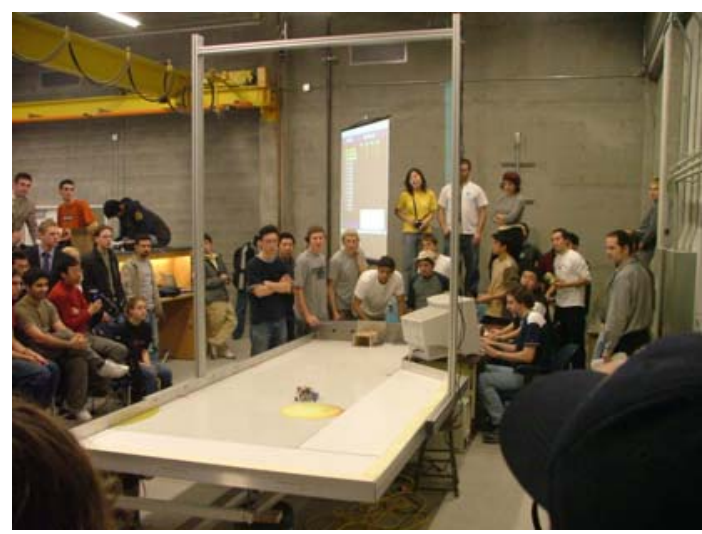

Figure 2. First project in MECH 223 recreation of the Cassini-Huygens mission to Saturn and Titan.
The second project focused on thermodynamics and fluid mechanics, and was phrased in terms of the transportation of dangerous goods by oceangoing vessels. Teams were required to design and construct a small cargo ship powered by compressed air and were awarded points based on the volume of cargo that they successfully transported through increasingly difficult manoeuvres. There was a cost score based on the volume of ship as well as the amount of compressed air used. For each run, teams had to predict their time to complete the manoeuvre and they lost points for not making their predicted transit time. Large penalties were imposed for boats that lost cargo, became stranded, or capsized. The competition was held at a large swimming pool; a photograph picturing the winning boat is shown in Figure 3.

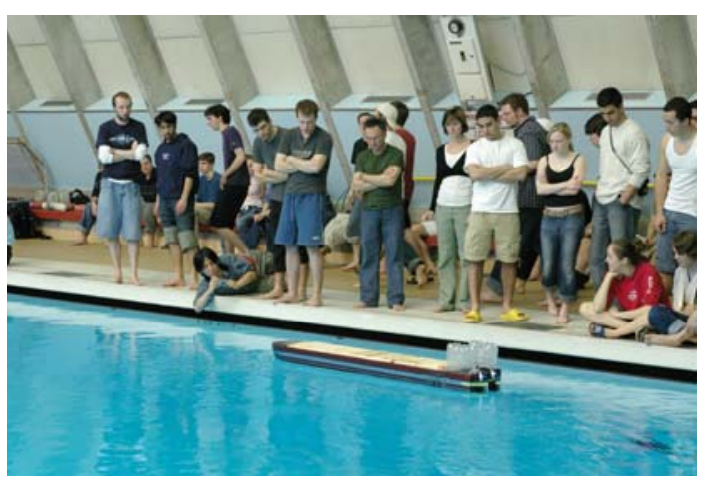

Figure 3. Second project in MECH 223 students built cargo vessels to transport bulk cargo across a pool using pressurized soda bottles as the energy source.

The structure of both project competitions was such that important parameters (for example, the playfield inclination in the first project) were not revealed until the beginning of a competition round. This forced teams to include adjustability in their designs and to develop and use analytical/numerical models for predicting performance. Human intervention was not permitted during the competition so teams utilized electromechanical systems for autonomous time and distance measurement, control actions, and so on.

\section{Design Labs and Machine Shop Sessions}

During the course, students had regular times set aside for meeting with one another and performing both machining and assembly tasks. Students had access to a shop, but for second year students, tool use was restricted - lathes and milling machines were not permitted, but 
bandsaws, drill presses, brakes and grinding wheels were.

\section{Computer Labs}

Students completed one 2 hour computer lab per week. In MECH 220, students had already been introduced to solid modelling and drafting; in MECH 223, we extended their abilities by teaching them how to create complete technical drawings, how to use a top-down design and modelling approach, and how to use mechanism simulation and animation tools. In addition, we conducted several labs on Ashby's computerbased material selection process.

\section{Special Tutorial Sessions}

We had three special sessions on group dynamics led by a pair of educational psychologists to help students understand that people see the world and respond to it in very different ways, and that if they understand these different approaches they can understand what might be going on in their teams. They are also taught how to be proactive in addressing issues in working with one another and are given several opportunities to talk with their teammates about how their group work is going. We believe that these session were very helpful in minimizing problems that arose during the term.

We also invited an industrial designer to class on two occasions to discuss the role of industrial design in larger product design projects and to run a 2 hour workshop on rapid visualization and communication of conceptual ideas. This was particularly useful in helping students understand what kinds of information are communicated at various stages of a design and what tools are appropriate for these purposes.

\section{Final Examinations}

In MECH 223, we were assigned two examination slots because of the increased credit load carried by the course. We took advantage of this to change the way the final exam was run. Instead of the traditional analysis-based exam questions, we ran two very different types of exam. The first aimed primarily at testing knowledge (mainly through multiple choice and short answer questions) and skills (through relatively short, focussed questions). The second exam was more like an engineering essay exam; we presented the students with a variant of a situation they had come across in their design projects and asked them to respond to it. For example, we told them that the rules for the cargo-carrying competition had been changed fuel was now considerably more expensive, freight rates were considerably higher if cargo could be delivered quickly, and cargo could no longer be loaded inside the hulls, but only on the deck. This made a catamaran design more plausible than it had been in the real competition. They had to decide whether or not it was reasonable to pursue a catamaran option (that is, to decide if this option would likely be able to turn a profit), and then present their reasoning in the form of a short essay with references to calculations that were included as appendices. Students were told that we would not look at their calculations unless they were properly referred to in the main text; this encouraged them to lay out their work carefully and to make decisions about WHAT they had to calculate, not just HOW to do so.

\section{EVALUATION BY STUDENTS}

At the completion of Mech 2, student perceptions were gauged using a series of anonymous surveys. The surveys were not mandatory and the response rates ranged from $52 \%$ to $58 \%$. Each course in Mech 2 had a separate survey which examined the effectiveness of various activities in that course.

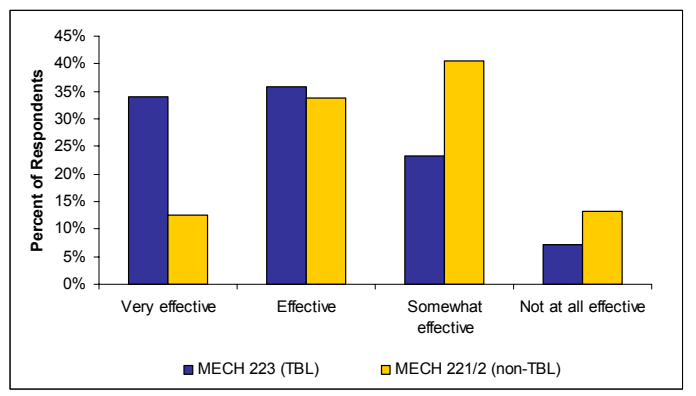

Figure 4. Comparison of student response to MECH 223 (Team-Based Learning) and the engineering-science-based Mech 2 courses.

For both the TBL design course (MECH 223) and the non-TBL engineering science courses (MECH 221 and MECH 222), students were asked to rate the effectiveness of the lectures/classes towards their professional development. Figure 4 shows a comparison of the student-rated effectiveness for the different courses. As shown, the TBL design classes received a significantly more positive rating than the non-TBL engineering science lectures. In particular, over $70 \%$ of students rated the TBL classes as either "effective" or "very effective" 
compared to $46 \%$ for the non-TBL classes. Likewise, while $7 \%$ of students rated the TBL classes as "not at all effective", this number jumped to $13 \%$ for the non-TBL classes.

When students were asked more specifically about the use of TBL in MECH 223, they rated it effective in general in terms of learning the course content, making the course more enjoyable, and developing team skills (Figure 5). Of particular interest, the TBL approach was rated as being either "effective" or "very effective" by $60 \%$ of the students for making the course more enjoyable, and by $75 \%$ of the students for developing team skills. Although comprehensive comparative data is not readily available, anecdotal evidence and exam scores suggest student understanding of the material in MECH 223 was at least as good as in similar courses from previous years. Thus, without diminishing the learning of content, the TBL approach seems to have enhanced course enjoyment and team skills development.

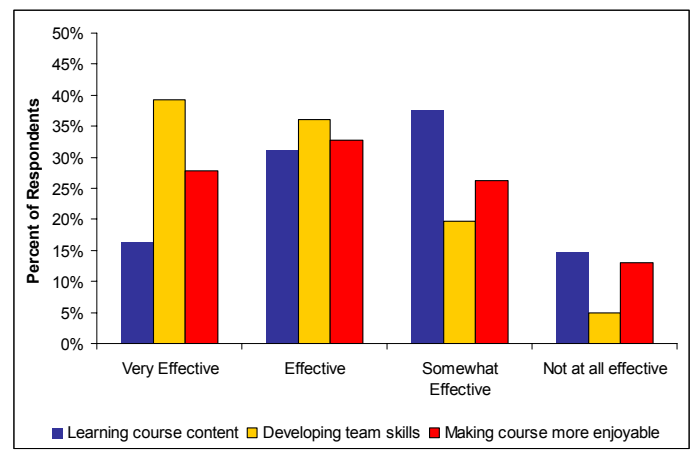

Figure 5. Student beliefs about value of TeamBased Learning relative to more conventional instructional modes on three criteria: course content, team skills and enjoyableness of course.

\section{LESSONS LEARNED}

Overall, we are very happy with the redesign of our second year design course. The projects were considerably more complex than projects previously conducted in second year and the design process the students followed was more formally specified than it has been in the past.

The use of Team-Based Learning was a revolution in the way we have traditionally taught our undergraduate courses, and for the most part we felt that it had a strong positive impact on the students and the classroom environment. Compared to a conventional design course, considerably more time and effort was required from instructors in creating in-class and tutorial activities. Care had to be taken in providing students with exercises that were sufficiently challenging yet still manageable within the time available. As a benefit, the amount of time spent preparing lecture notes was greatly reduced. Overall, the classes were much more exciting and engaging for students and instructors alike.

\section{CONCLUSIONS}

We are already confident that we have made a dramatic improvement to the second year curriculum and the students appear to feel much the same way.

\section{ACKNOWLEDGEMENTS}

We gratefully acknowledge the support of Jim Sibley, Sophie Spiridonoff and Billy Lam in the Centre for Instructional Support. We also thank the students of Mech 2 for their forbearance during our growing pains. We are glad that they have enjoyed this experience and appreciate all their comments and responses to our instructional experiments.

\section{REFERENCES}

Team-Based Learning: A Transformative Use of Small Groups in College Teaching, edited by Larry K. Michaelsen, Arletta B. Knight, and L. Dee Fink. Stylus Publishing, Sterling VA 